трудов Ангарской государственной технической академии: Изд-во АГТА, г. Ангарск. 2005. T. 1. № 1. С. 187-192.

3. Коновалов, Ю.В. Исследование пуска электроприводов с двигателями переменного тока / Ю.В. Коновалов, Д.О. Гера- симов // Современные технологии. Системный анализ. Моделирование: Изд-во ИрГУПС, г. Иркутск. - 2012. № 4 (36). С. 142149.

\title{
ELECTROMAGNETIC INFLUENCE OF THREE-PHASE LINES OF ELECTRIC TRANSMISSION AND TRACTION NETWORK 25KV
}

\begin{abstract}
Аннотация. B статье представлены методика и результаты моделирования электромагнитных полей, создаваемых линиями электропередачи 25 кB и тяговыми сетями 25 кB. При этом применялись методы определения режимов электроэнергетических систем (ЭЭС) на базе фазных координат, в основу которых положены модели элементов в виде решетчатых схем замещения с полносвязной топологией. Эти модели и методы реализованы в программном комплексе Fazonord-APC, обеспечивающем моделирование стационарных режимов ЭЭС, а также определение напряженностей электромагнитного поля, которое создается линиями электропередачи различного конструктивного исполнения.
\end{abstract}

Ключевые слова: электроэнергетические системы, линии электропередачи, электромагнитная безопасность.

Abstract. The article presents the methodology and results of modeling electromagnetic fields generated by $25 \mathrm{kV}$ power lines and $25 \mathrm{kV}$ traction networks. In this case, methods were used to determine the modes of electric power systems (EPS) based on phase coordinates, which are based on element models in the form of lattice equivalent circuits with a fully connected topology. These models and methods are implemented in the Fazonord-ARS software package, which provides simulation of stationary EES modes, as well as determination of electromagnetic field strengths, which are created by power lines of various designs.

Keywords: electrical power systems, power lines, electromagnetic safety.

Электротехнический персонал электроустановок тягового электроснабжения подвергается воздействию комплекса вредных факторов производственной среды, основными из которых являются электрическое (ЭП) и магнитное поля (МП).

В связи с этим, в последние годы при проектировании и эксплуатации электроустановок высокого напряжения все большее внимание уделяется их электромагнитной совместимости с жизнедеятельностью человека. Это, в первую очередь, связано с проведением исследований в области влияния электромагнитных полей на здоровье человека. В частности, ранее не было четкой оценки негативного влияния на жизнедеятельность людей магнитных полей промышленной частоты. Главной причиной то- му явилась невозможность человеком ощутить магнитное поле в момент его воздействия и проявление последствий этого влияния лишь по истечении достаточно большого промежутка времени.

Основными объектами электроэнергетики, при эксплуатации которых возникают опасные магнитные поля промышленной частоты, являются линии электропередачи (ЛЭП) различного конструктивного исполнения, подстанции высокого напряжения и тяговые сети (ТС) переменного тока, которые из-за электромагнитной неуравновешенности создают сравнительно большие электрические и магнитные поля. Следует отметить, что воздействию электромагнитного поля вблизи ЛЭП и ТС может подвергаться как специализированный персонал, так и 
проживающие или работающие около ЛЭП и ТС люди. Следовательно, в настоящее время достаточно остро стоит вопрос разработки методик расчета параметров электромагнитных полей промышленной частоты в электро-энергетических устройствах различного назначения и, соответственно, разработки мер по снижению их интенсивности.

Существует методика определения полей многопроводных систем, включая тяговые сети и линии электропередачи [1-3], при предварительном расчете режима электроэнергетической системы, которая может содержать многопроводные линии, однофазные и трехфазные трансформаторы разных типов, тяговые сети переменного тока и перемещающиеся тяговые нагрузки $[2,3]$. Разработанный программный комплекс Fazonord [3] объединяет возможности расчетов режимов в фазных координатах и одновременные расчеты напряженностей электромагнитного поля (ЭМП).
Данная статья является развитием идеи в направлении детального анализа структуры электромагнитного поля ЛЭП 25 кВ и железной дороги с тяговой сетью 25 кВ.

Особенность режимов системы электроснабжения железной дороги (СЭЖД) связана с тем, что линии электропередачи, проложенные вдоль трассы железной дороги переменного тока, подвержены электрическому и магнитному влияниям тяговой сети $[2,4$, 5]. На рис. 1 представлена типичная осциллограмма наведенного напряжения. Электрическое влияние создает напряжение нулевой последовательности на проводах ЛЭП 610-35 кВ с изолированной нейтралью, что увеличивает погрешности учета электрической энергии для потребителей, питающихся от технологических ЛЭП «провод-рельс» и «два провода-рельс», но не приводит к заметным гармоническим искажениям.

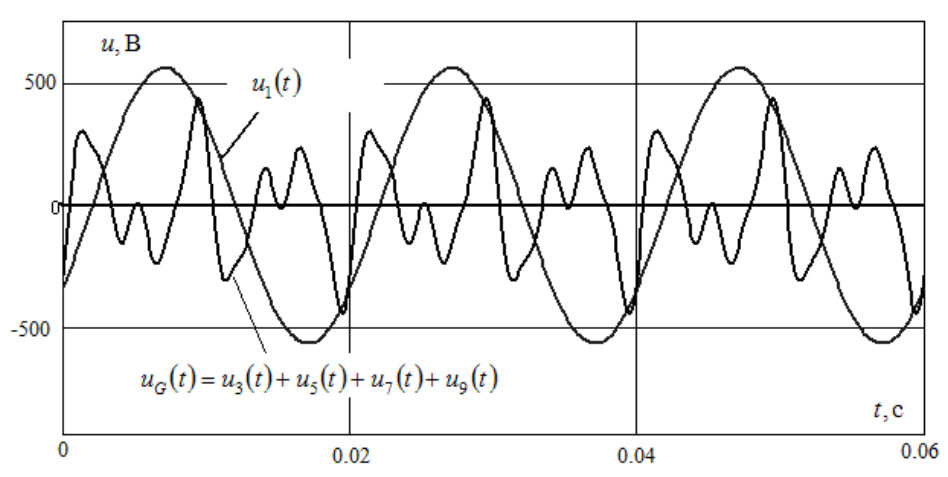

Рисунок 1 - Магнитное влияние. Типичная осциллограмма наведенного напряжения: $u_{1}(t)$ - наведенное напряжение первой гармоники; $u_{G}(t)$ - результирующее напряжение нечетных гармоник с третьей по девятую; ток в контактной сети составлял $300 \mathrm{~A}$

Напряжение магнитного влияния пропорционально частоте влияющего тока и потому имеет значительные гармонические искажения; при этом величина результирующего напряжения гармонических искажений u_G (t) соизмерима по амплитуде с наведенным напряжением первой гармоники $\mathrm{u} \_1$ (t) (рис. 1). Проанализированные выше особенности СЭЖД необходимо учитывать при разработке методов анализа электромагнитной безопасности.
Трехфазные линии электропередачи при симметричной нагрузке являются электромагнитно сбалансированными. Однофазные тяговые сети отличаются несбалансированностью и создают значительно большие ЭМП при прочих равных условиях. Для подтверждения этого факта на рис. 2 - 5 и в табл. 1 приведены результаты определения ЭМП трехфазной ЛЭП и тяговой сети 25 кВ. 

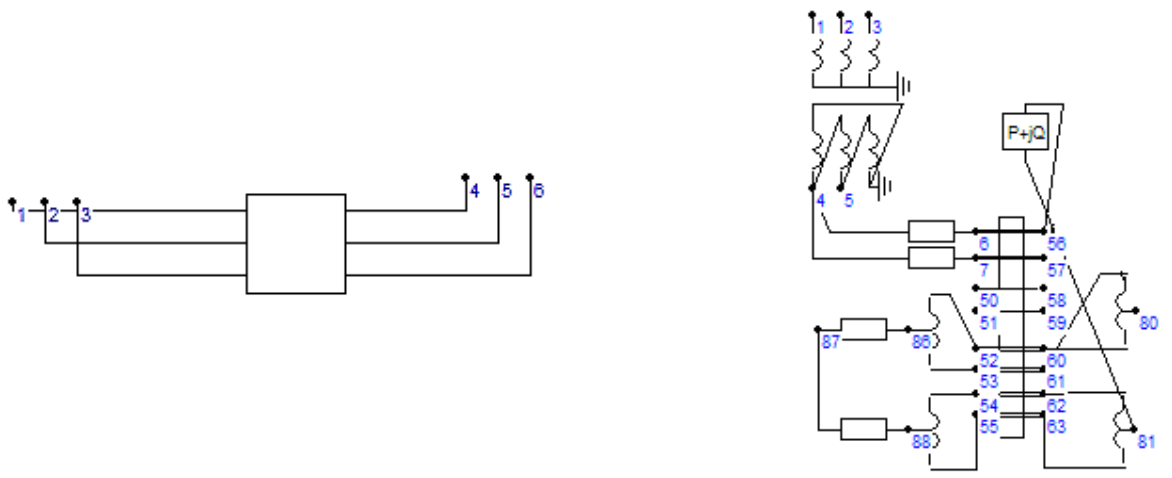

a)

б)

Рисунок 2 - Схемы расчетных моделей: $\mathrm{a}$ - трехфазная ЛЭП с фазными напряжениями проводов 25 кВ; б - однофазная тяговая сеть 25 кВ

Протяженность ТС и ЛЭП была принята равной 2 км. Нагрузки ЛЭП заданы в $2+$ j2 MB•A на фазу. В тяговой сети нагружена контактная подвеска одного пути, величина нагрузки принята в $6+\mathrm{j} 6 \mathrm{MB} \cdot \mathrm{A}$. Таким обра-

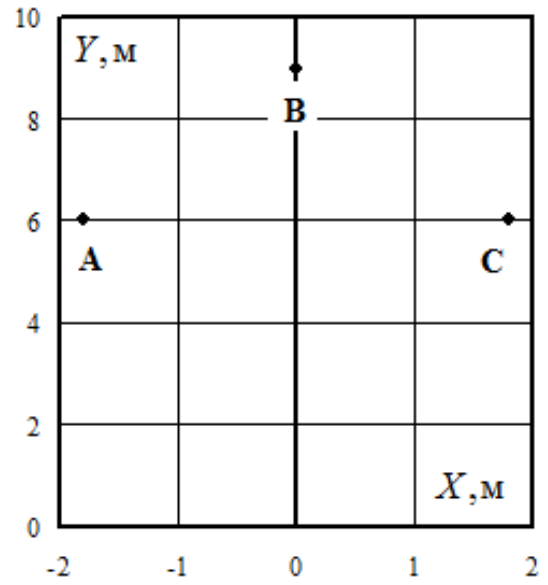

a) зом, по трехфазной ЛЭП и ТС передается одинаковая мощность.

Координаты проводов ЛЭП и ТС показаны на рис. 3.

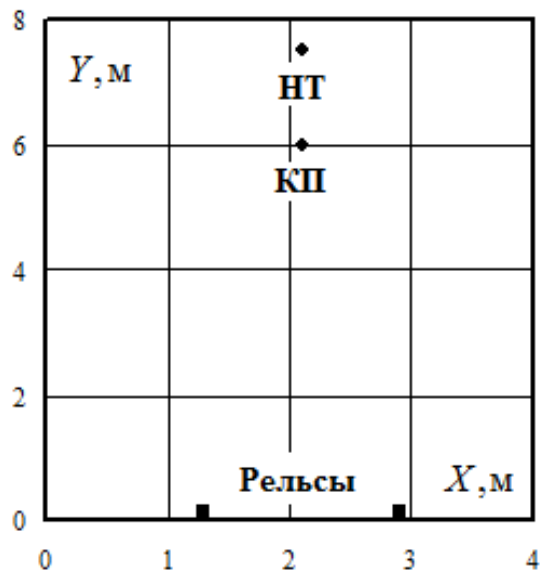

б)

Рисунок 3 - Координаты токоведущих частей:

a - ЛЭП 25 кВ (А, В, С - координаты соответствующих фаз);

б - ТС 25 кВ (НТ- несущий трос, КП - контактный провод)

Сводные результаты расчета режимов ЛЭП и ТС представлены в табл. 2. В этой таблице Е_(MAX) - напряженность электри- ческого поля; Н_(MAX) - напряженность магнитного поля; индекс TN относится к тяговой сети, а индекс TL - к ЛЭП.

Таблица 1

Результаты расчета режимов ЛЭП и ТС

\begin{tabular}{|c|c|c|c|c|}
\hline \multirow{2}{*}{$\begin{array}{c}\text { Узлы } \\
\text { с соответствии } \\
\text { с расчетной моделью } \\
\text { рис. 2) }\end{array}$} & \multicolumn{2}{|c|}{ Напряжения } & \multicolumn{2}{c|}{ Токи } \\
\cline { 2 - 5 } & $\begin{array}{c}\text { действующее значе- } \\
\text { ние, кB }\end{array}$ & $\begin{array}{c}\text { начальная фаза, } \\
\text { град }\end{array}$ & $\begin{array}{c}\text { действующее зна- } \\
\text { чение, A }\end{array}$ & $\begin{array}{c}\text { начальная фаза, } \\
\text { град }\end{array}$ \\
\hline 4 & 26,50 & $-0,05$ & 107,81 & 134,84 \\
\hline 5 & 26,50 & $-120,05$ & 107,79 & 14,84 \\
\hline 6 & 26,50 & 119,95 & 107,78 & $-105,17$ \\
\hline
\end{tabular}




\begin{tabular}{|c|c|c|c|c|}
\hline 56 & 26,11 & 26,11 & 326,49 & 132,64 \\
\hline 62 & 0,12 & 0,12 & 164,73 & $-47,35$ \\
\hline 63 & 0,12 & 0,12 & 161,77 & $-47,37$ \\
\hline
\end{tabular}

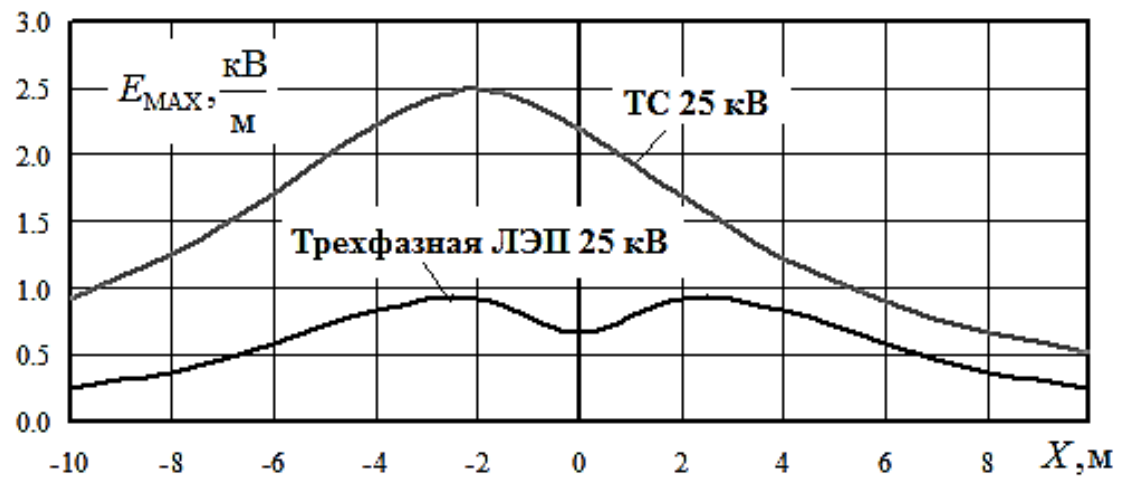

Рисунок 4 - Зависимости амплитудных значений напряженности ЭП от координаты $X$

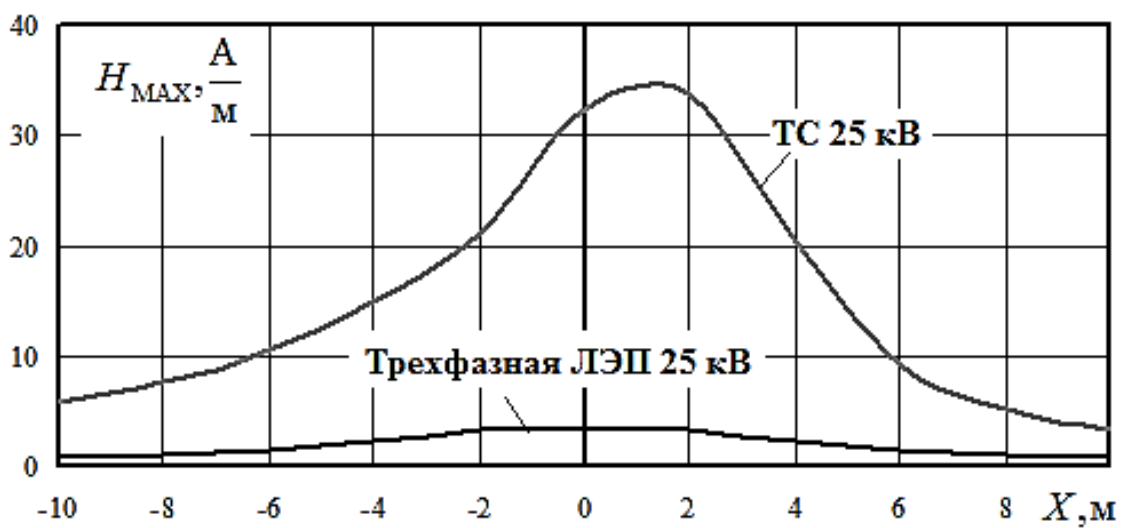

Рисунок 5 - Зависимости амплитудных значений напряженности МП от координаты $X$

Таблица 2

Сводные показатели ЭМП

\begin{tabular}{|c|c|c|c|c|}
\hline \multirow{2}{*}{ Показатель } & \multirow{2}{*}{ Параметр } & \multicolumn{2}{|c|}{ Тип линии } & \multirow{2}{*}{$\lambda_{E M F}=\frac{X_{\mathrm{MAX}}^{(T N)}}{X_{\mathrm{MAX}}^{(T L)}}$} \\
\hline & & Трехфазная ЛЭП 25 кВ & $\mathrm{TC}$ & \\
\hline \multirow{2}{*}{$E_{\mathrm{MAX}}, \mathrm{\kappa B} / \mathrm{M}$} & Среднее & 0,60 & 1,44 & 2,39 \\
\hline & Максимум & 0,93 & 2,49 & 2,68 \\
\hline \multirow{2}{*}{$H_{\mathrm{MAX}}, \mathrm{A} / \mathrm{M}$} & Среднее & 1,92 & 14,87 & 7,75 \\
\hline & Максимум & 3,62 & 33,65 & 9,30 \\
\hline
\end{tabular}

Заключение

Представлены положения методики и результаты моделирования электромагнитных полей, создаваемых линиями электропередачи 25 кВ и тяговыми сетями 25 кВ. Показано, что максимальные и средние значения напряженности электрического поля тяговой сети в два с половиной раза превыша- ют аналогичные показатели для ЛЭП. По магнитному полю различия существенно больше и достигают почти десятикратной величины для максимальных значений. Это связано с тем, что напряжения ТС и ЛЭП практически не отличаются, однако токи тяговой сети значительно превышают токи ЛЭП. 


\section{СПИСОК ЛИТЕРАТУРЫ}

1. Буякова Н.В., Закарюкин В.П., Крюков А.В. Электромагнитная безопасность в системах электроснабжения железных дорог: моделирование и управление. Ангарск, 2014. - 382 с.

2. Закарюкин В.П., Крюков А.В. Сложнонесимметричные режимы электрических систем. - Иркутск: Иркут. ун-т, 2005. 273 c.

3. Крюков А.В, Закарюкин В.П. Методы совместного моделирования систем тягового и внешнего электроснабжения железных дорог переменного тока. - Иркутск, 2011. - 160 c.
4. Крюков А.В., Закарюкин В.П., Кобычев Д.С. Моделирование электромагнитных влияний контактной сети железных дорог на смежные линии электропередачи // Электротехнические комплексы и системы управления. 2009. № 1. С. 2-7.

5. Крюков А.В., Закарюкин В.П., Кобычев Д.С. Определение наведенных напряжений с учетом несинусоидальности токов контактной сети железных дорог переменного тока // Научные проблемы транспорта Сибири и Дальнего Востока. 2009. № 2. С. 315 319.

к.т.н., ст.н.с. РАН, профессор кафедры «Электроснабжение промышленных предприятий», ФГБОУ ВО «Ангарский государственный технический университет», тел.: 89025698207

Тумурова Наталья Васильевна, студентка гр. ЭЭпр-16-2 кафедры «Электроснабжение промышиенных предприятий» ФГБОУ ВО «Ангарский государственный технический университет»

ПУТИ И МЕТОДЫ СОВЕРШЕНСТИВОВАНИЯ ВЗАИМООТНОШЕНИЙ ЭНЕРГОСНАБЖАЮЩИХ ОРГАНИЗАЦИЙ И ПОТРЕБИТЕЛЕЙ ЭНЕРГИИ

Golovshchikov V.O., Tumurova N.V.

\section{WAYS AND METHODS OF IMPROVING RELATIONSHIPS OF ENERGY-SUPPLYING ORGANIZATIONS AND ENERGY CONSUMERS}

Аннотация. B статье рассмотрены основные проблемы, возникающие при взаимоотношениях энергоснабжающих организащий и потребителей энергии и методь их решения, направленные на повышение эффективности взаимоотношений поставщиков и покупателей энергетических ресурсов.

Ключевые слова: реформа электроэнергетики, энергетические компании, электрическая и тепловая энергия, продажи и покупка энергоресурсов.

Abstract. The article discusses the main problems that arise in the relationship of energy supplying organizations and energy consumers and methods for solving them, aimed at improving the efficiency of relations between suppliers and buyers of energy resources.

Keywords: reform of the electric power industry, energy companies, electric and thermal energy, sales and purchase of energy resources.

В 2019 году исполняется 27 лет с начала реформирования всей социальноэкономической и политической жизни России после распада СССР и 18 лет с начала официального реформирования электроэнергетики страны. Большинство представителей научно-технического сообщества признают, что основные цели и задачи реформирования электроэнергетики, сформулированные в известной «Концепции Стратегии РАО «ЕЭС
России» (концепция: «5+5» (1998-2003 и 2003-2008 г.г.), в Постановлении Правительства РФ №526 (июль 2001 г.) «О реформировании электроэнергетики» и в Федеральном законе №35 (2003 год) «Об электроэнергетике» либо полностью не выполнены, либо выполнены только частично [1-7]. Вот некоторые итоги реформирования:

1. В качестве концептуальной основы реформирования были применены «западные 